\title{
Analysis of Flue Gas Emission Data from Fluidized Bed Combustion Using Self-Organizing Maps
}

\author{
Mika Liukkonen, ${ }^{1}$ Mikko Heikkinen, ${ }^{1}$ Eero Hälikkä, ${ }^{2}$ Teri Hiltunen, ${ }^{2}$ and Yrjö Hiltunen ${ }^{1}$ \\ ${ }^{1}$ Department of Environmental Science, University of Eastern Finland, P.O. Box 1627, 70211 Kuopio, Finland \\ ${ }^{2}$ Foster Wheeler Energia Oy, Operations, Engineering \& Services, P.O. Box 201, 78201 Varkaus, Finland \\ Correspondence should be addressed to Mika Liukkonen, mika.liukkonen@uef.fi
}

Received 17 March 2010; Accepted 12 August 2010

Academic Editor: Junbin B. Gao

Copyright (C) 2010 Mika Liukkonen et al. This is an open access article distributed under the Creative Commons Attribution License, which permits unrestricted use, distribution, and reproduction in any medium, provided the original work is properly cited.

\begin{abstract}
Efficient combustion of fuels with lower emissions levels has become a demanding task in modern power plants, and new tools are needed to diagnose their energy production. The goals of the study were to find dependencies between process variables and the concentrations of gaseous emission components and to create multivariate nonlinear models describing their formation in the process. First, a generic process model was created by using a self-organizing map, which was clustered with the k-means algorithm to create subsets representing the different states of the process. Characteristically, these process states may include high- and lowload situations and transition states where the load is increased or decreased. Then emission models were constructed for both the entire process and for the process state of high boiler load. The main conclusion is that the methodology used is able to reveal such phenomena that occur within the process states and that could otherwise be difficult to observe.
\end{abstract}

\section{Introduction}

The international efforts to reduce harmful process emissions, such as nitrogen oxides $\left(\mathrm{NO}_{\mathrm{x}}\right)$, sulfur dioxide $\left(\mathrm{SO}_{2}\right)$, and carbon monoxide (CO), are increasingly affecting the production of energy. For example, the tightening environmental legislation [1] and rising fuel prices are increasing the requirements for the efficiency of combustion processes. Nonetheless, efficient combustion of fuels with lower emissions is increasingly difficult in power plants. The pressure to lift the price of electricity is causing an additional challenge because the producers are forced to search for cheaper fuels of lower quality, such as waste, recycled fuels or poor-quality coal. When it comes to the reduction of emissions, these fuels are extremely challenging.

The different gaseous emission components have several harmful effects on the environment and humanbeings. For example, the $\mathrm{NO}_{\mathrm{x}}$, although not being considered a greenhouse gas, can cause acid fallout and participates in the formation of photochemical smog and ozone in big cities [2]. Sulfur dioxide has the potential to damage vegetation and to acidify freshwater resources [3]. Carbon monoxide is a poisonous gas that poses a threat for both the humans [4] and the environment [5] and is also often linked to increased levels of carbon dioxide, which is a greenhouse gas.

Fortunately, the data gathered from the combustion process may involve essential information on the performance of the process and on different phenomena influencing the formation of emissions and the energy efficiency of combustion. This information can be extracted by using suitable data mining methods. If used and interpreted in an appropriate way, this information can be valuable in the analysis and optimization of the process. Therefore, it is reasonable to develop such data analysis methods that can respond to the new challenges in the production of energy.

The self-organizing map (SOM) [6] was originally developed by Kohonen in the early 1980s. Thereafter, the use of the self-organizing map algorithm for different purposes has produced a diversified range of applications. The SOM has been used in many different practical applications, including exploratory data analysis, pattern recognition, speech analysis, industrial and medical diagnostics, robotics and instrumentation, and even control [6,7]. Moreover, Kasslin et al. [8] and Alhoniemi et al. [9] have introduced 


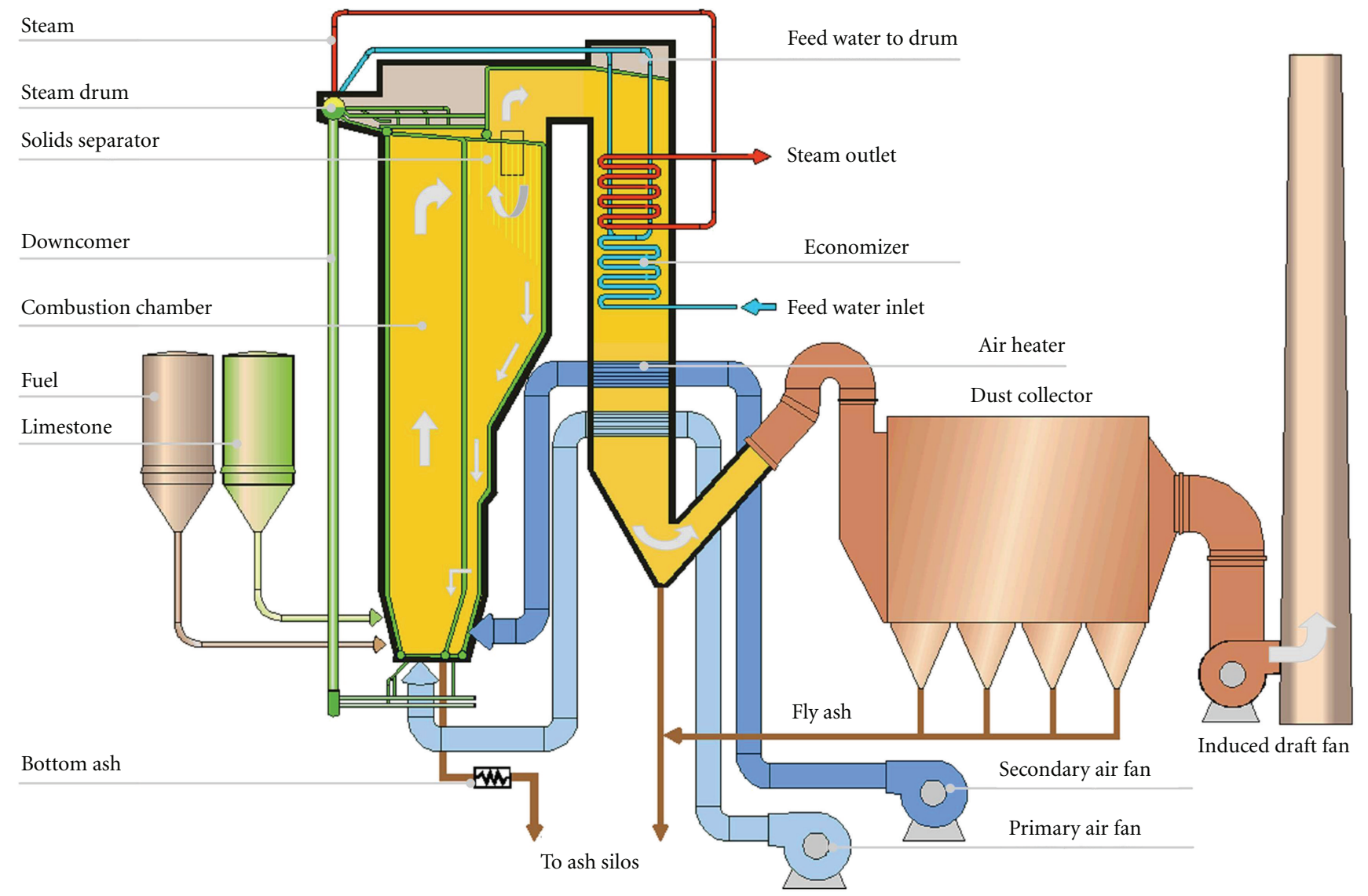

FIgURE 1: Cross-section of the circulating fluidized bed boiler.

SOM-based applications to process monitoring and modeling in many industrial cases.

The SOM has offered a good platform for many different intelligent applications [10-17]. Furthermore, several of our recent studies $[11,18-20]$ have shown the power of SOM in the modeling of the fluidized bed combustion process. These contributions present a relatively large variety of applications related to process modeling, involving, for instance, modeling and identification of process states, emission modeling, and variable selection and even optimization. In this paper we expand the methodology presented in [20] for the analysis of $\mathrm{NO}_{\mathrm{x}}$ to the modeling of other gaseous emissions in a CFB power plant.

\section{Process and Data}

Fluidized bed combustion is a widely used technology for producing energy. The process is designed principally for the combustion of solid fuels such as coal or biomass. A conventional circulating fluidized bed boiler (see Figure 1), or a CFB, comprises a combustion chamber, a separator, and a return leg to circulate the bed particles. The bed material is composed of sand, fuel ash, and some sulfur capturing material. Sulfur dioxide removal from flue gas during the combustion process is possible, for example, by adding limestone in the bed, which is considered to be one of the most important advantages of fluidized bed combustion [21]. The mixture of bed material is fluidized by the primary combustion air brought in from the bottom of the chamber.

In CFBs the bed particles are in consistent movement with the flue gases because of high fluidizing velocities. The particles advance through the combustion chamber into a separator, where the larger particles are extracted and diverted back to the chamber. In the meantime, the finer particles are separated from the cycle. Characteristic combustion temperatures in CFB boilers are between 850 and $900^{\circ} \mathrm{C}$. The advantages of CFBs include multifuel combustion, low $\mathrm{NO}_{\mathrm{x}}$ emissions due to relatively low temperatures, and desulfurization during combustion, which means that no additional cleaning systems are needed for sulfur emissions. Reduction of emissions at an early stage in the combustion chamber is one of the principal reasons for employing the fluidized bed concept for combustion [22].

The original process data were averaged to the resolution of 15 minutes. The data matrix used in the modeling included 10000 rows with 38 variables in columns.

\section{Methodology}

Self-organizing maps were used in the analysis of the process emissions. The data processing stages and their outcome are presented in Figure 2. The area of high boiler load was 


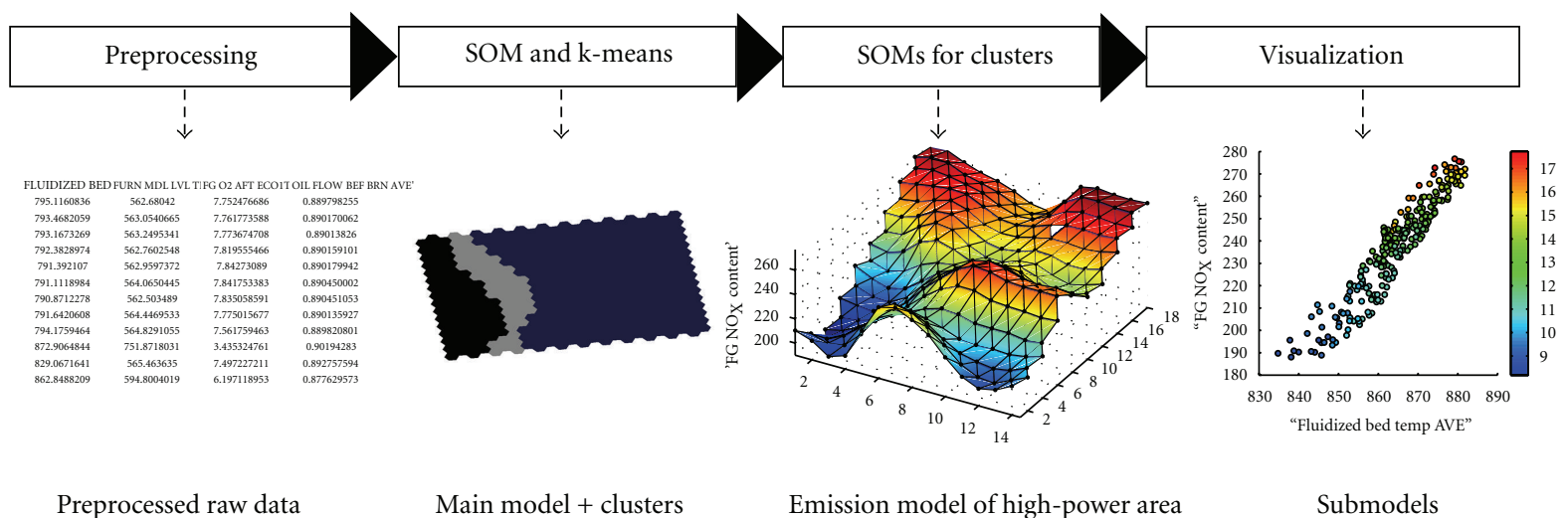

Figure 2: Data analysis stages and their outcome.

selected to the analysis because it best presents the typical situation in the combustion process.

3.1. Self-Organizing Map (SOM). The common use of a selforganizing map (SOM) [6] is for mapping $n$-dimensional input vectors to nodes, or neurons, for example, in a twodimensional lattice, or map. The map of neurons describes variations in the statistics of the input data, and the topological organization of the original data is maintained on the SOM by connecting the input vectors sharing common features to the same or neighboring neurons. The size of the map can be varied according to the application; the bigger the map is, the more details appear. In contrast, a smaller map can be chosen to ensure an adequate generalization capability.

The learning of SOM involves an unsupervised process. First, the reference vectors are initialized randomly by using an even distribution whose limits are determined by the input data. During learning, the input vectors are categorized successively into best matching units, $B M U$ s, on the map. The BMU is the neuron whose reference vector has the smallest $n$-dimensional Euclidean distance to the input vector. At the same time, the nearest neighbors of the BMU are activated as well, according to a neighborhood function (e.g., Gaussian distribution). Ultimately the reference vectors of all activated neurons are updated.

In summary, the training of the SOM involves the following stages:

(1) initialize the map,

(2) find BMU for the input vector by using Euclidean distance,

(3) move the reference vector of the BMU towards the input vector,

(4) move the reference vectors of the neighboring neurons towards the input vector,

(5) repeat steps (2)-(4) for all input vectors successively,

(6) repeat steps (2)-(5) by using a smaller learning rate factor (fine tuning),

(7) find the final BMUs for input vectors.
The SOM Toolbox [23] was used in the analysis under a Matlab (version 7.6) software (Mathworks Inc., Natick, MA, USA, 2008) platform. The parameters of the SOM and the size of the map were determined by experimental testing. Linear initialization, batch training algorithm [24], and a Gaussian neighborhood function were used in the training. By using the Matlab, the batch computation version of the SOM is significantly faster than the basic SOM $[23,24]$ and is thus more applicable to industrial processes involved with large data sets. The map was taught with 10 epochs, and the initial neighborhood had the value of 6 .

3.2. K-Means Clustering. K-means [25] is a so-called partitional clustering algorithm [26] based on the calculation of squared errors. K-means is one of the most popular clustering algorithms because it is easy to implement. The stages of the algorithm are as follows:

(1) define $k$ cluster centers and assign $k$ random data vectors to them,

(2) address each data vector to the cluster with the most similar cluster center,

(3) update the cluster centers to new memberships,

(4) in case the criterion for convergence is not met, go to step (2). For example, minimal decrease of squared error can be used to stop iteration.

The optimal number of clusters can be determined by using the Davies-Bouldin index [27]. Thus, a priori knowledge of the optimal cluster structure is unnecessary.

\section{Results}

4.1. Generic Model and Process States. A self-organizing map having $24^{*} 16$ neurons was created to obtain the generic process model. The emission models in Figure 3 involve the use of the whole data set before the identification of process states. The markers in the figures represent the neurons of the SOM, which are plotted in a 2-dimensional space in respect to their variable components shown in the axes.

After modeling, the process states of high, medium, and low boiler load were identified. This was done by clustering 


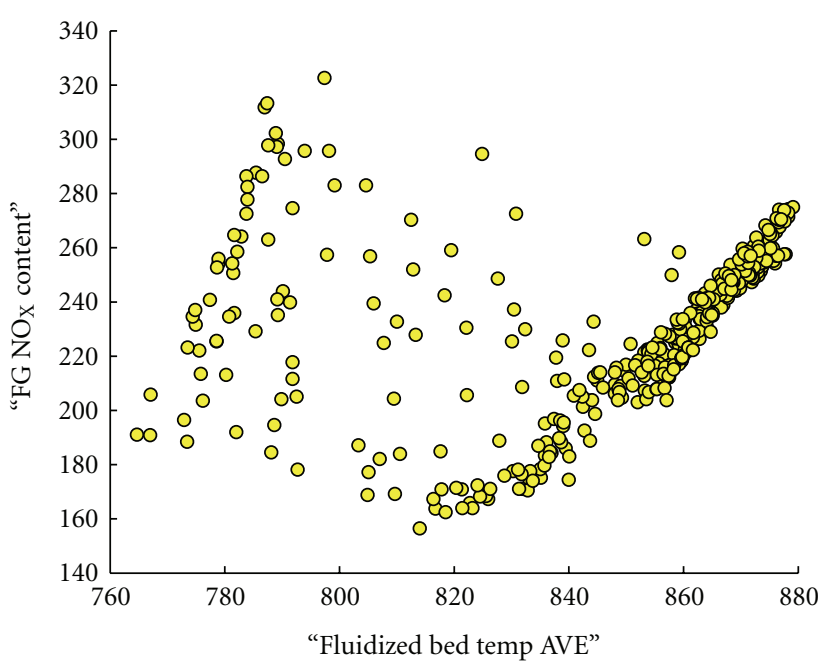

(a)

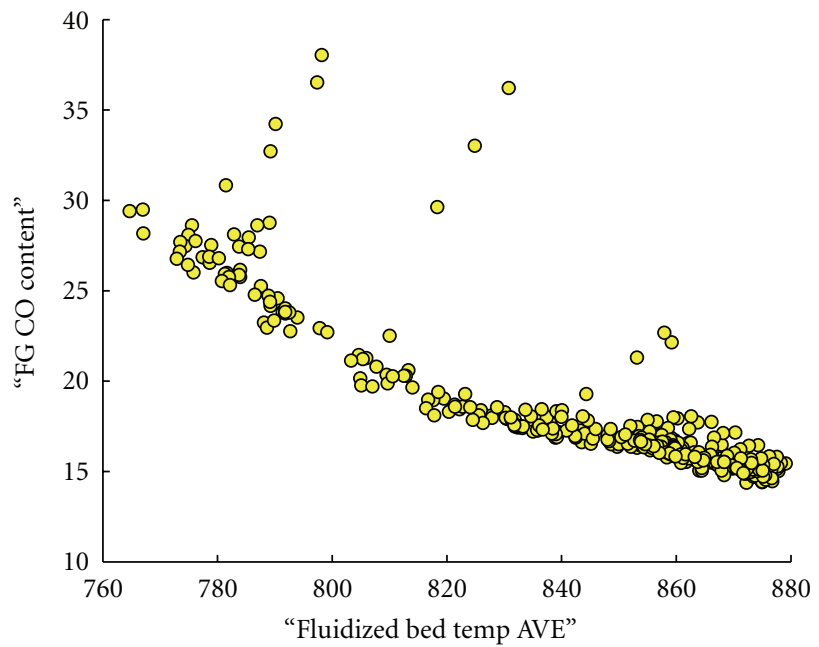

(b)

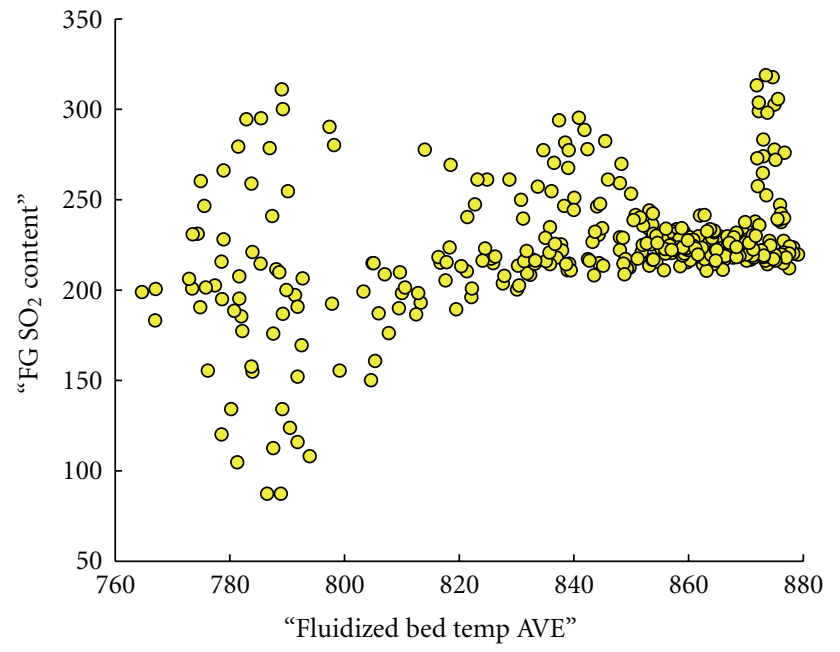

(c)

Figure 3: Emission models after creating a $24^{*} 16 \mathrm{SOM}$. (a) $\mathrm{NO}_{\mathrm{x}}$, (b) $\mathrm{CO}$, and (c) $\mathrm{SO}_{2}$ content $\left[\mathrm{mg} / \mathrm{Nm}^{3}\right]$ of flue gas (FG) as a function of the bed temperature $\left[{ }^{\circ} \mathrm{C}\right]$ by using the reference vectors of SOM neurons.

the reference vectors of the $24 * 16$ SOM with the $\mathrm{k}$-means algorithm, as presented in Figure 4 . As can be seen, in this case the borders achieved by clustering seem to follow the degree of steam flow, that is, the boiler load.

4.2. Process State of High Power. For emission models, a SOM having $18^{*} 14$ neurons was created within the process state of high steam flow. The emission models for $\mathrm{NO}_{\mathrm{x}}, \mathrm{CO}$, and $\mathrm{SO}_{2}$ are presented in the Figures 5(a), 5(b), and 5(c), respectively. In Figures 6(a), 6(b), and 6(c), each emission component is presented as a function of the bed temperature, and the color scale indicates the deviation of the bed temperature. The markers in these figures represent the neurons of the SOM, which are plotted in a 2-dimensional space in respect to their variable components shown in the axes. Figures 7(a) and 7 (b) illustrate the $\mathrm{SO}_{2}$ content of flue gas as a function of the fluidized bed temperature and the total limestone flow, respectively. The color scale indicates the deviation of the middle level temperature in the furnace.

\section{Discussion}

Previously, the SOM has been considered a visual and functional method in tasks related to process monitoring, diagnostics, and optimization of circulating fluidized bed boilers $[11,18-20]$. The results of this paper support our earlier findings. All together, the SOM and k-means provide a simple and visual way to diagnose the combustion process. Furthermore, the results indicate that the method can be used to define process states and illustrate them in a user-friendly way. As a whole, it is useful to monitor the states of the process, because they provide supplementary information on the operation of the energy plant and on the formation of different emission components. 


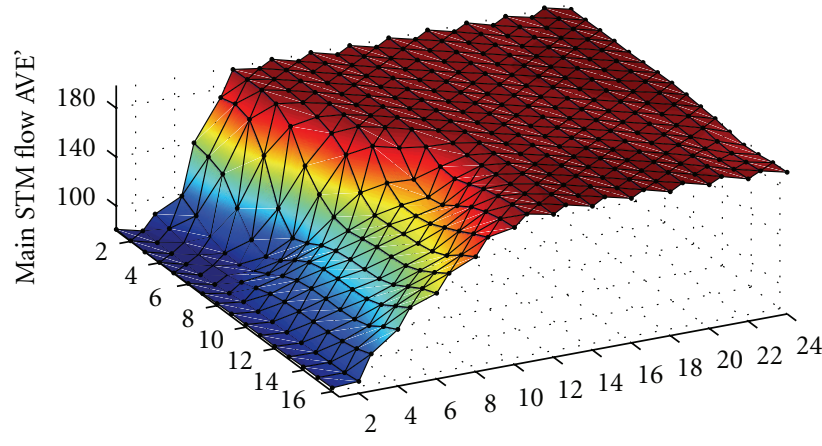

(a)

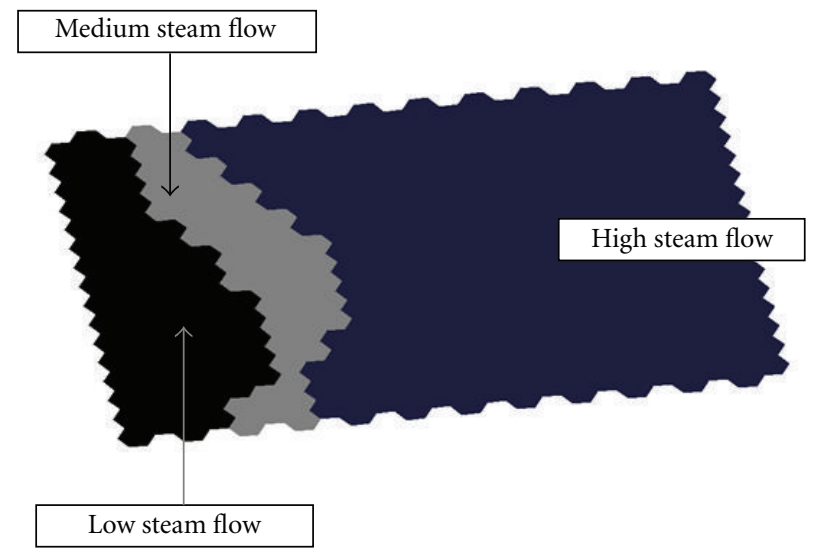

(b)

FIGURE 4: (a) The behavior of the main steam flow on a $24^{*} 16$ SOM and (b) a clustered SOM $(k=3)$, which shows the separation of process states into three locations on the SOM.

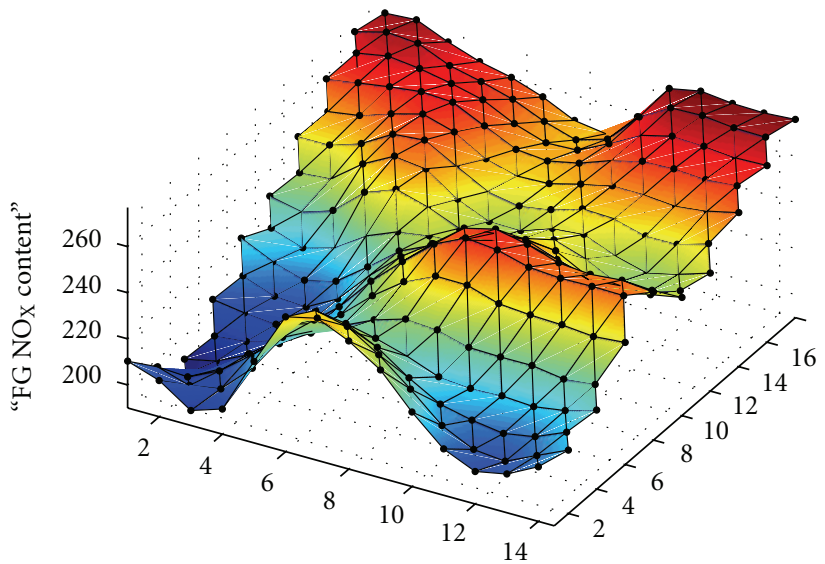

(a)

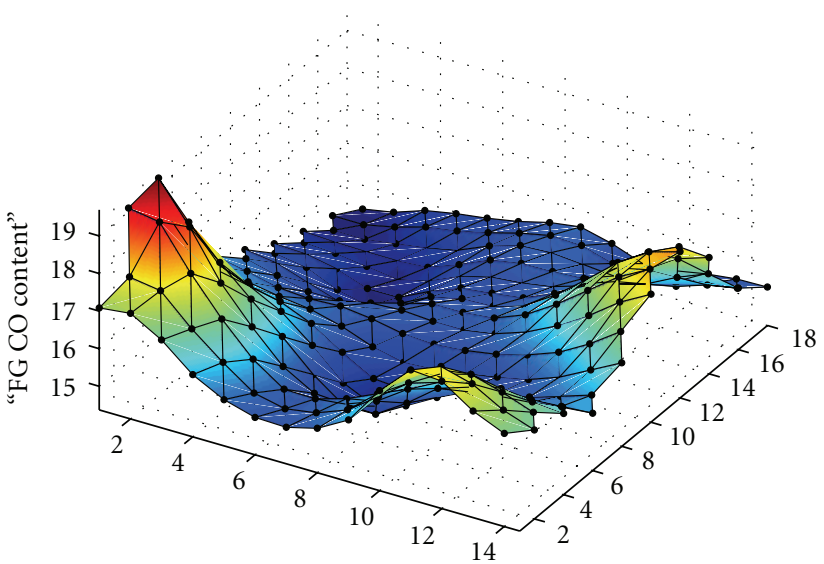

(b)

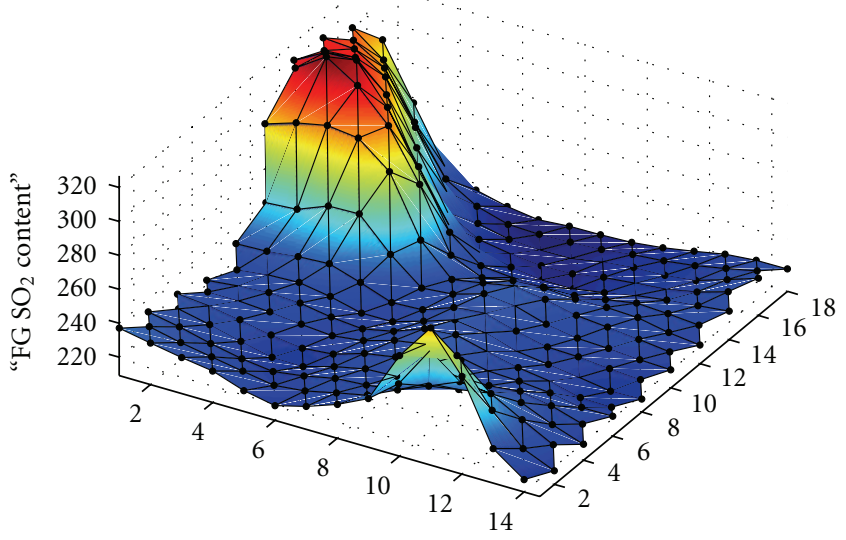

(c)

FigurE 5: The component planes of different emission components $\left[\mathrm{mg} / \mathrm{Nm}^{3}\right]$, (a) $\mathrm{NO}_{\mathrm{x}}$, (b) $\mathrm{CO}$, and (c) $\mathrm{SO}_{2}$, on $18^{*} 14 \mathrm{SOM}$ grids after modeling the process state of high-steam flow. 


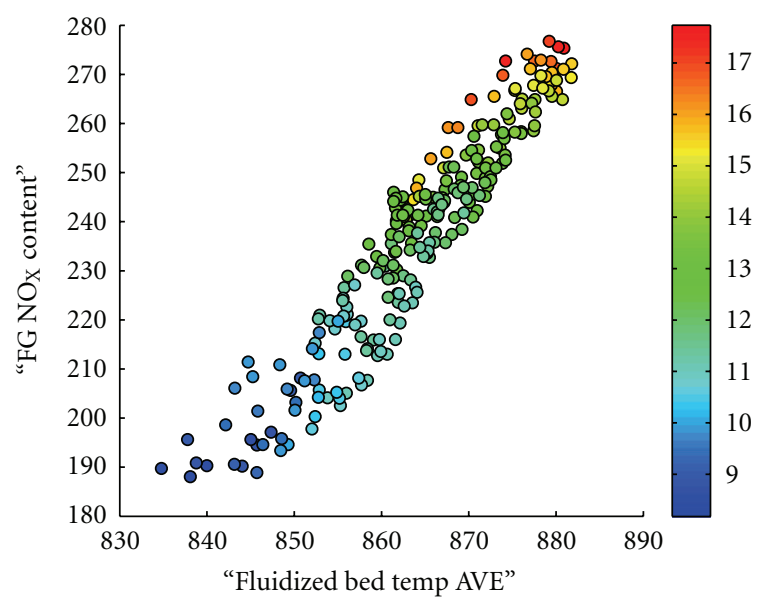

(a)

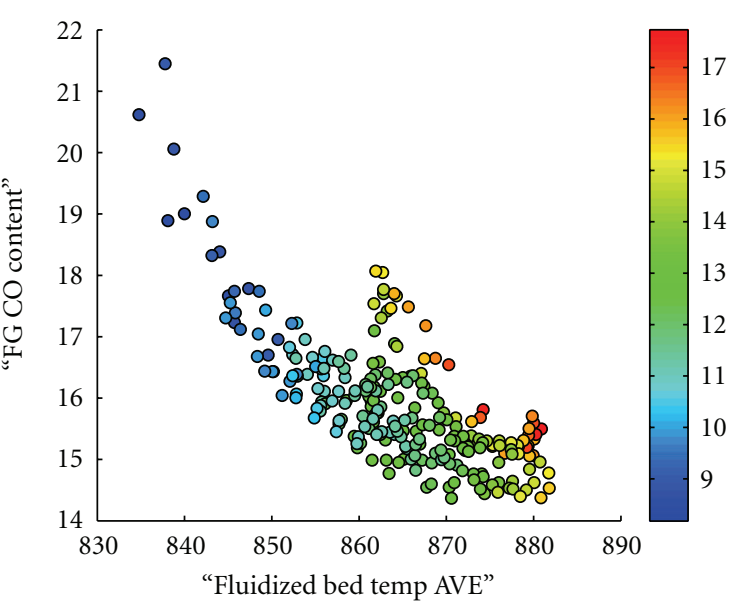

(b)

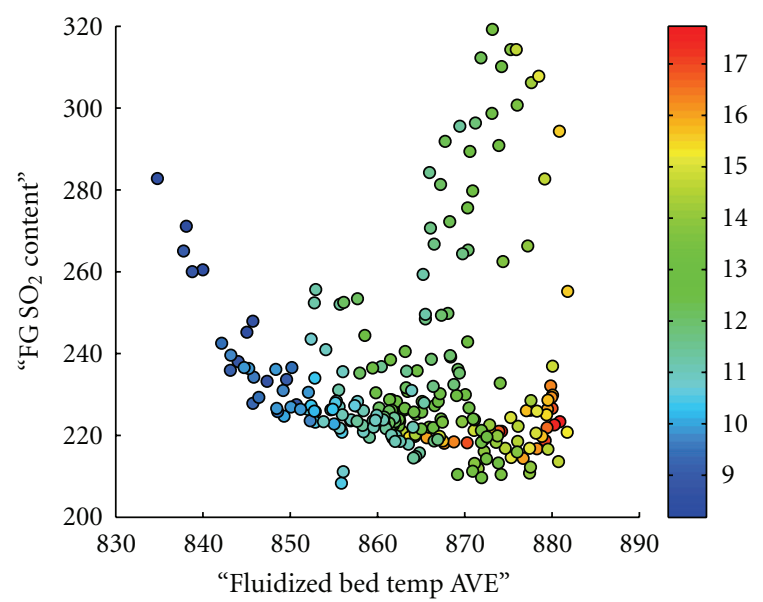

(c)

FIGURE 6: Emission models of the process state of high-steam flow. (a) $\mathrm{NO}_{\mathrm{x}}$, (b) $\mathrm{CO}$, and (c) $\mathrm{SO}_{2}$ content $\left[\mathrm{mg} / \mathrm{Nm}^{3}\right]$ of flue gas (FG) as a function of the bed temperature $\left[{ }^{\circ} \mathrm{C}\right]$ by using the reference vectors of SOM neurons. Color scale indicates the deviation of the bed temperature $\left[{ }^{\circ} \mathrm{C}\right]$.

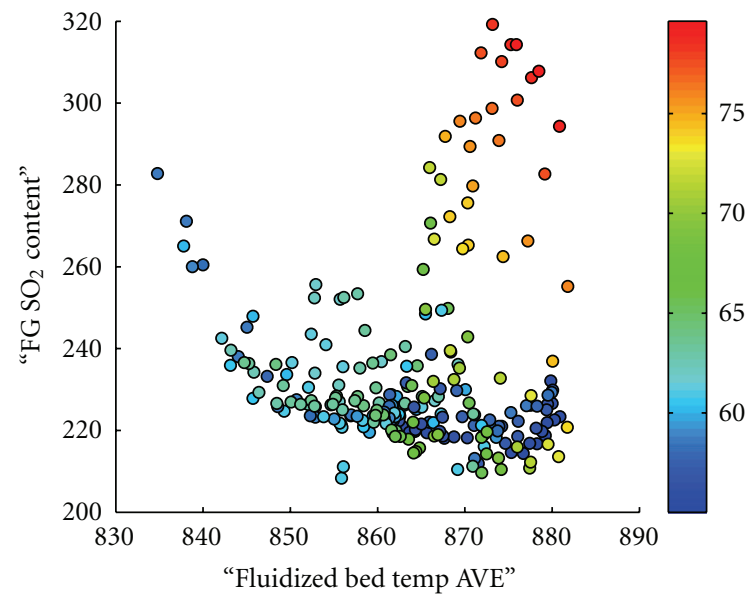

(a)

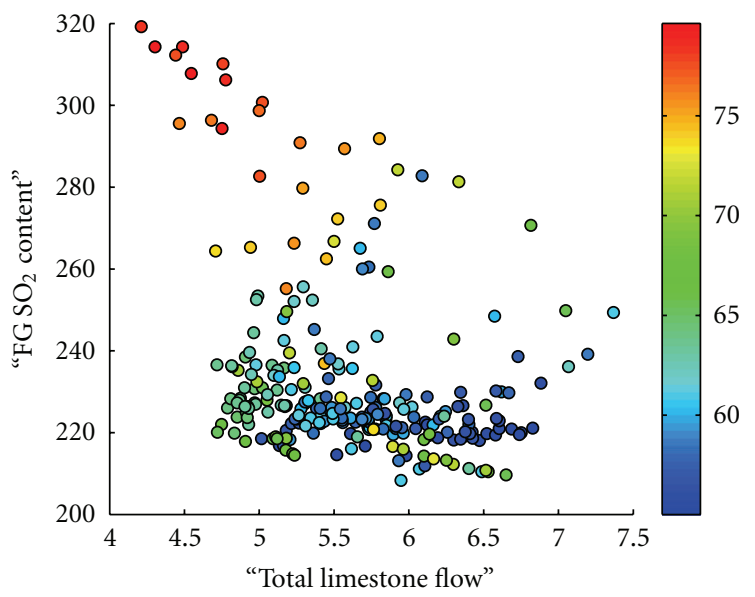

(b)

Figure 7: Flue gas (FG) $\mathrm{SO}_{2}$ content $\left[\mathrm{mg} / \mathrm{Nm}^{3}\right]$, (a) as a function of the bed temperature [ ${ }^{\circ} \mathrm{C}$ ] and (b) as a function of the limestone flow $[\mathrm{kg} / \mathrm{s}]$, by using the reference vectors of SOM neurons in the process state of high-steam flow. Color scale indicates the deviation of the furnace middle level temperature $\left[{ }^{\circ} \mathrm{C}\right]$. 
The reduction of harmful emissions can be a difficult task in fluidized bed energy plants, especially because they use inhomogeneous fuels with an altering quality, such as coal, bark, or biomass. The results of this study reflect the complexity of the problem. Figure 2 indicates the difficulty of modeling the emissions. Carbon monoxide is the only emission component that could be modeled easily without the information on the different process states.

The approach used makes it possible to make a deep diagnosis on the formation of emissions. Perhaps the foremost conclusion can be drawn from Figure 4, is that, the areas of minimum emission rates are at variance with each other in the process state of high power. Situations with relatively low $\mathrm{NO}_{\mathrm{x}}$ and $\mathrm{SO}_{2}$ emissions can be found on the map, but those areas are also characterized by a relatively high concentration of CO. This leads to compromises in the minimization of emissions.

In respect to nitric oxides (see Figure 6(a)), the most distinct factor involved with their formation in the state of high power is the bed temperature; however, the relationship is not clear in respect to the generic process model (see Figure 3(a)). It seems, nonetheless, that the $\mathrm{NO}_{\mathrm{x}}$ concentration increases when there is instability in the bed temperatures (see Figure 6(a)). In addition, an important observation is that the $\mathrm{NO}_{\mathrm{x}}$ content of flue gas could be reduced by as much as $10 \%\left(27 \mathrm{mg} / \mathrm{Nm}^{3}\right)$ by optimizing the process.

Higher bed temperatures seem to favor the reduction of $\mathrm{CO}$ in the flue gas (see Figures 3(b) and 6(b)). In this respect, the $\mathrm{CO}$ emissions behave conversely to the $\mathrm{NO}_{\mathrm{x}}$ emissions. Nevertheless, the effect of the deviation of the bed temperature is similar on both the $\mathrm{CO}$ and $\mathrm{NO}_{\mathrm{x}}$ concentrations: a stable bed temperature generally favors the reduction of these emissions. Even as high as $18 \%$ $\left(3 \mathrm{mg} / \mathrm{Nm}^{3}\right)$ reduction of $\mathrm{CO}$ can be achieved by optimizing the process.

Figure 6(c) indicates that the formation of $\mathrm{SO}_{2}$ can be reduced in the process state of high power with a higher bed temperature; however, it seems that there are cases where the $\mathrm{SO}_{2}$ concentration becomes suddenly high in the higher temperatures. Generally speaking, it seems that the formation of $\mathrm{SO}_{2}$ is a more complex issue than the other emission components that were studied.

Figure 7(a) suggests that a high deviation of the middle level temperature in the furnace explains the high concentrations of $\mathrm{SO}_{2}$ in the higher bed temperatures. However, Figure 7(b) suggests that a certain level of limestone flow should be maintained to keep the $\mathrm{SO}_{2}$ concentration below $300 \mathrm{mg} / \mathrm{Nm}^{3}$. It is presumable that the changes in the sulfur content of fuel can affect greatly the formation of sulfur dioxide in the process, which can explain the high deviation in the $\mathrm{SO}_{2}$ concentration with higher bed temperatures.

In a more general level, the results show that the data analysis method presented can be excellent in cases where large amounts of data have to be processed to get a rapid diagnosis on process emissions. In addition, clustering the data samples into subcategories, or process states, provides supplementary value and extra accuracy to the emission models. Furthermore, the ability of the method to reveal nonlinear and multivariate interactions is a major advantage. For these reasons, the analysis method presented is a powerful choice for modeling industrial processes.

\section{Conclusions}

Solutions to several environmental problems are currently being searched for. It is evident that in the future also the energy plants have to be able to produce their energy with a lesser amount of harmful, gaseous emissions. The method presented provides a fruitful way to diagnose processes and offers new possibilities for the analysis of process emissions in the near future.

For instance, presently only a few gaseous emission components are included in the international emission trading. Nonetheless, the emission regulations are becoming tighter worldwide due to the growing interests in different environmental issues. As new emission types will be added to the trading of emissions in the future, the method can be used for emission cost modeling after the definition of an appropriate cost function. Alternatively, the methodology can be used to more generic process optimization, for example, to optimize the total profit of producing steam in fluidized bed boilers.

\section{References}

[1] Directive 2009/29/EC of the European Parliament and of the Council of 23 April 2009 amending Directive 2003/87/EC so as to improve and extend the greenhouse gas emission allowance trading scheme of the Community. European Council, 2009.

[2] R. Zevenhoven, P. Kilpinen et al., "Control of Pollutants in Flue Gases and Fuel Gases," Report TKK-ENY-4, Laboratory of Energy Engineering and Environmental Protection, Helsinki University of Technology, Espoo, Finland, 2002, http://users.abo.fi/rzevenho/gasbook.html.

[3] J. N. Cape, D. Fowler, and A. Davison, "Ecological effects of sulfur dioxide, fluorides, and minor air pollutants: recent trends and research needs," Environment International, vol. 29, no. 2-3, pp. 201-211, 2003.

[4] J. A. Raub, M. Mathieu-Nolf, N. B. Hampson, and S. R. Thom, "Carbon monoxide poisoning - a public health perspective," Toxicology, vol. 145, no. 1, pp. 1-14, 2000.

[5] D. Schwela, "Air pollution and health in urban areas," Reviews on Environmental Health, vol. 15, no. 1-2, pp. 13-42, 2000.

[6] T. Kohonen, self-organizing maps, Springer, Berlin, Germany, 2001.

[7] M. Oja, S. Kaski, and T. Kohonen, "Bibliography of selforganizing map (SOM) papers: 1998-2001 addendum," Neural Computing Surveys, vol. 3, pp. 1-156, 2002.

[8] M. Kasslin, J. Kangas, and O. Simula, "Process State Monitoring Using self-organizing maps," in Artificial Neural Networks 2, I. Aleksander and J. Taylor, Eds., vol. 1, North-Holland, Amsterdam, The Netherlands, 1992.

[9] E. Alhoniemi, J. Hollmén, O. Simula, and J. Vesanto, "Process monitoring and modeling using the self-organizing map," Integrated Computer-Aided Engineering, vol. 6, no. 1, pp. 3-14, 1999.

[10] J. Abonyi, S. Nemth, C. Vincze, and P. Arva, "Process analysis and product quality estimation by self-organizing maps with 
an application to polyethylene production," Computers in Industry, vol. 52, no. 3, pp. 221-234, 2003.

[11] M. Heikkinen, T. Hiltunen, M. Liukkonen, A. Kettunen, R. Kuivalainen, and Y. Hiltunen, "A modelling and optimization system for fluidized bed power plants," Expert Systems with Applications, vol. 36, no. 7, pp. 10274-10279, 2009.

[12] M. Heikkinen, H. Poutiainen, M. Liukkonen, T. Heikkinen, and Y. Hiltunen, "SOM-based subtraction analysis to process data of an activated sludge treatment plant," in Proceedings of the 6th International Conference on Mathematical Modelling (MATHMOD '09), I. Troch and F. Breitenecker, Eds., Vienna University of Technology, Vienna, Austria, 2009.

[13] S.-L. Jämsä-Jounela, M. Vermasvuori, P. Endén, and S. Haavisto, "A process monitoring system based on the Kohonen self-organizing maps," Control Engineering Practice, vol. 11, no. 1, pp. 83-92, 2003.

[14] T. Kohonen, E. Oja, O. Simula, A. Visa, and J. Kangas, "Engineering applications of the self-organizing map," Proceedings of the IEEE, vol. 84, no. 10, pp. 1358-1383, 1996.

[15] M. Liukkonen, E. Havia, H. Leinonen, and Y. Hiltunen, "Application of self-organizing maps in analysis of wave soldering process," Expert Systems with Applications, vol. 36, no. 3, pp. 4604-4609, 2009.

[16] M. Liukkonen, E. Havia, H. Leinonen, and Y. Hiltunen, "Quality-oriented optimization of wave soldering process by using self-organizing maps," Applied Soft Computing, vol. 11, no. 1, pp. 214-220, 2011.

[17] M. Vermasvuori, P. Endén, S. Haavisto, and S.-L. JämsäJounela, "The use of Kohonen self-organizing maps in process monitoring," in Proceedings of the 1st International Symposium on Intelligent Systems, vol. 3, pp. 2-7, 2002.

[18] M. Heikkinen, A. Kettunen, E. Niemitalo, R. Kuivalainen, and Y. Hiltunen, "SOM-based method for process state monitoring and optimization in fluidized bed energy plant," in Proceedings of the 15th International Conference on Artificial Neural Networks (ICANN '05), vol. 3696 of Lecture Notes in Computer Science, pp. 409-414, Springer, 2005.

[19] M. Liukkonen, M. Heikkinen, T. Hiltunen, E. Hälikkä, R. Kuivalainen, and Y. Hiltunen, "Modeling of process states by using artificial neural networks in a fluidized bed energy plant," in Proceedings of the 6th International Conference on Mathematical Modelling, I. Troch and F. Breitenecker, Eds., Vienna University of Technology, Vienna, Austria, 2009.

[20] M. Liukkonen, M. Heikkinen, E. Hälikkä, R. Kuivalainen, and Y. Hiltunen, "Emission analysis of a fluidized bed boiler by using self-organizing maps," in Proceedings of the International Conference on Adaptive and Natural Computing Algorithms (ICANNGA '09), M. Kolehmainen, P. Toivanen, and B. Beliczynski, Eds., vol. 5495, Springer, 2009.

[21] Ž. Ćojbašić, L. Ćojbašić, V. Nikolić, N. Radojković, and M. Vukić, "Computational intelligence modeling and control of flue gas emission in FBC process," Mechanical Engineering, vol. 1, no. 9, pp. 1263-1274, 2002.

[22] B. Leckner, "Fluidized bed combustion: mixing and pollutant limitation," Progress in Energy and Combustion Science, vol. 24, no. 1, pp. 31-61, 1998.

[23] J. Vesanto, J. Himberg, E. Alhoniemi, and J. Parhankangas, "self-organizing map in Matlab: the SOM toolbox," in Proceedings of the Matlab DSP Conference, pp. 35-40, 1999, http://www.cis.hut.fi/projects/somtoolbox/.

[24] T. Kohonen, "Analysis of processes and large data sets by a selforganizing method," in Proceedings of the 2nd International Conference on Intelligent Processing and Manufacturing of Materials, vol. 1, pp. 27-36, IEEE Service Center, 1999.
[25] J. MacQueen, "Some methods for classification and analysis of multivariate observations," in Proceedings of the 5th Berkeley Symposium on Mathematical Statistics and Probability, vol. 1, pp. 281-297, University of California Press, Berkeley, Calif, USA, 1967.

[26] A. K. Jain, M. N. Murty, and P. J. Flynn, "Data clustering: a review," ACM Computing Surveys, vol. 31, no. 3, pp. 316-323, 1999.

[27] D. L. Davies and D. W. Bouldin, "A cluster separation measure," IEEE Transactions on Pattern Analysis and Machine Intelligence, vol. 1, no. 2, pp. 224-227, 1979. 

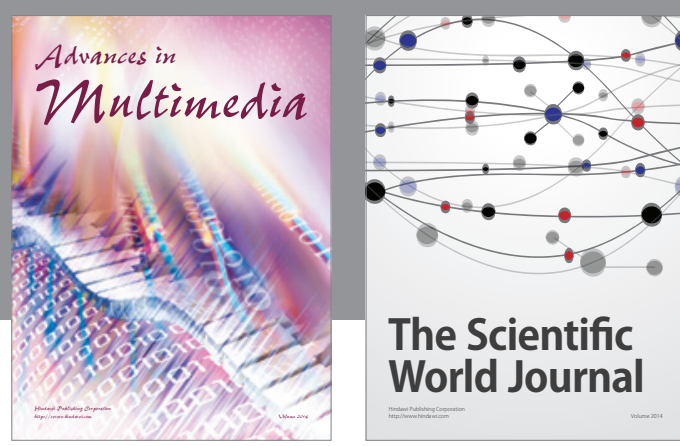

The Scientific World Journal
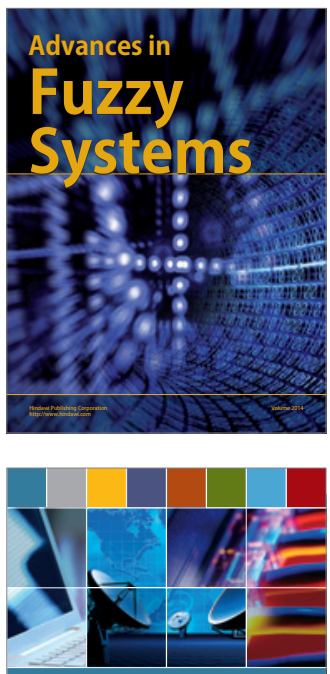

Computer Networks and Communications
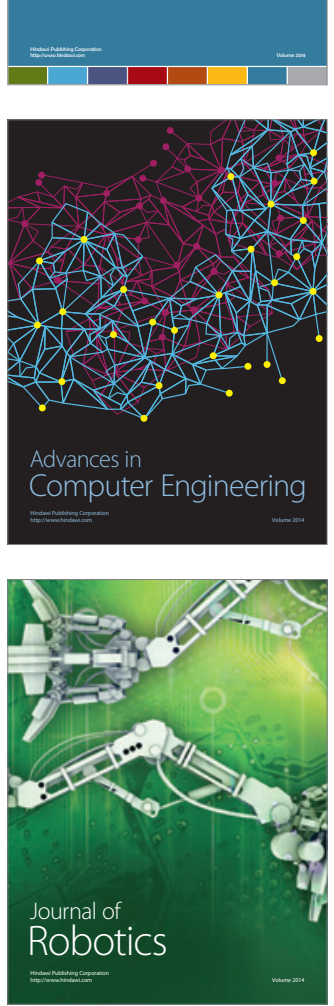
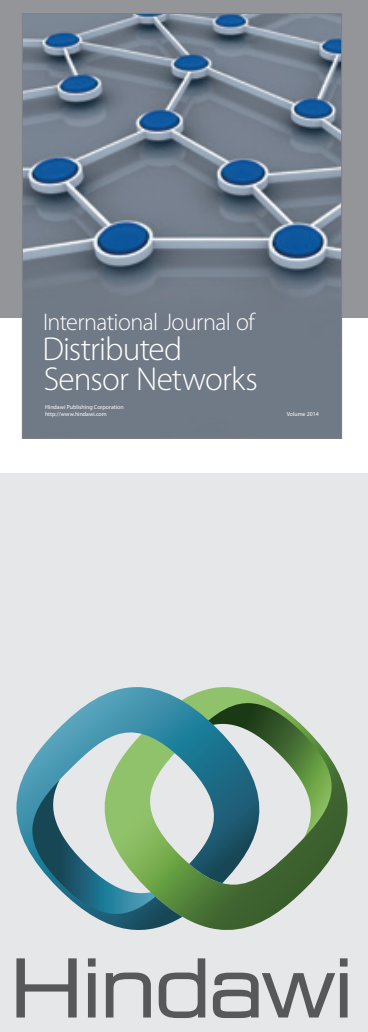

Submit your manuscripts at

http://www.hindawi.com
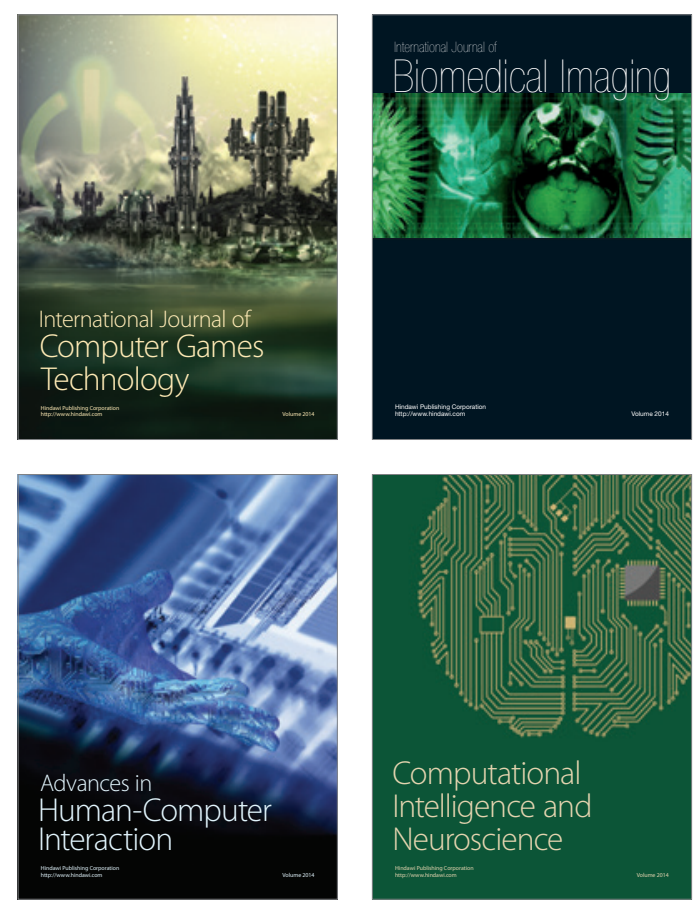
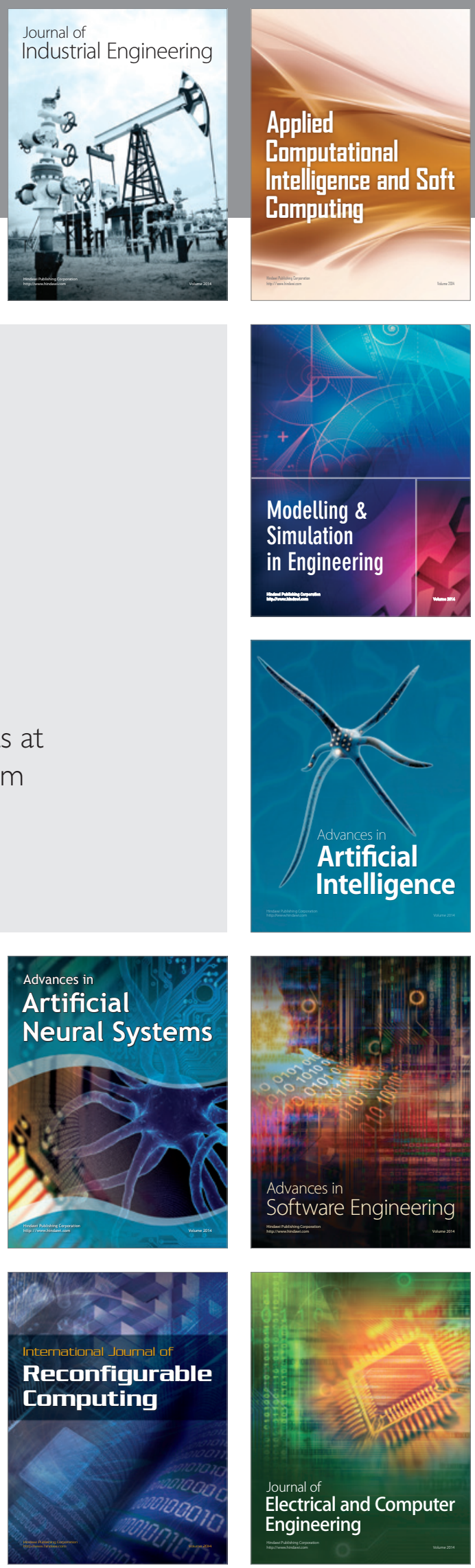